Gut, 1985, 26, 364-368

\title{
Uptake and subcellular localisation of bismuth in the gastrointestinal mucosa of rats after short term administration of colloidal bismuth subcitrate
}

\author{
D STIEL, D J MURRAY, AND T J PETERS \\ From the Division of Clinical Cell Biology, MRC Clinical Research Centre, Harrow, Middlesex
}

SUMmaRY Despite the topical action of colloidal bismuth subcitrate in promoting the healing of peptic ulcers, slight absorption of bismuth from the gastrointestinal tract has been reported in colloidal bismuth subcitrate-treated animals and man. The uptake and subcellular distribution of bismuth by the gastrointestinal tract of rats after 24 hours of colloidal bismuth subcitrate administration was studied. Mucosal uptake of bismuth (mean \pm SEM nmol/g protein) by gastric fundus $(8 \cdot 85 \pm 1 \cdot 0)$ and antrum $(7 \cdot 23 \pm 1 \cdot 50)$ was similar, but was significantly less than duodenum $(19.2 \pm 3.7, \mathrm{p}<0.05)$, jejunum $(26.9 \pm 2.4, \mathrm{p}<0.001)$ or ileum $(22.4 \pm 2 \cdot 2, \mathrm{p}<0.001)$. Bismuth concentrations in antral and duodenal mucosae fell progressively over 72 hours to approximately $10 \%$ of initial concentrations $(\mathrm{p}<0.02)$. Subcellular fractionation studies of colloidal bismuth subcitrate treated duodenal enterocytes showed a brush border membrane and cytosolic localisation. These data suggest that some gastrointestinal mucosal uptake of bismuth occurs in colloidal bismuth subcitrate treated rats.

Colloidal bismuth subcitrate is a useful drug in the treatment of peptic ulceration ${ }^{1-3}$ but its precise mechanism of action is unknown. Although it is believed to act topically at the ulcer base, low levels of bismuth have been shown in blood and urine of humans ${ }^{4}$ and in several organs in the laboratory animals $^{56}$ after administration of colloidal bismuth subcitrate, indicating that some absorption does occur. The site of gastrointestinal absorption of colloidal bismuth subcitrate and whether this occurs via the transcellular or paracellular route, are not known. It is possible that uptake by the surface epithelial cells of the stomach and duodenum is inherent in the ulcer healing properties of colloidal bismuth subcitrate.

The aims of the present study are to examine the site and time course of mucosal uptake of bismuth and to determine the subcellular distribution of bismuth within the gastrointestinal mucosa after short term administration of colloidal bismuth subcitrate to rats.

Address for correspondence: Prof T J Peters, Division of Clinical Cell Biology, Clinical Research Centre, Watford Road, Harrow, Middlesex HA1 3UJ.

Received for publication 8 June 1984

\section{Methods}

\section{ANIMALS}

Male Sprague-Dawley rats weighing 200-250 g were kept in mesh bottomed cages to minimise coprophagy. After a 24 hour fast, animals in the treatment group were allowed free access to drinking water containing colloidal bismuth subcitrate, $10 \mathrm{mg} / \mathrm{ml}$ (De Nol; Brocades Ltd, UK). The bismuth content of this solution was found to be $19.0 \mu \mathrm{mol} / \mathrm{ml}$ : control animals drank tap water. $\left[{ }^{51} \mathrm{Cr}\right]$-sodium chromate, $1 \mu \mathrm{Ci} / \mathrm{ml}\left(3.7 \times 10^{4} \mathrm{~Bq} / \mathrm{ml}\right)$ (Amersham International, Amersham, Bucks, UK) was added to the drinking water of both groups as a non-absorbable marker. ${ }^{7}$ After 24 hours, the animals were killed by cervical dislocation. The gastrointestinal tract, from the forestomach to the terminal ileum, was removed in continuity and rinsed five times with ice-cold $150 \mathrm{mmol} / \mathrm{l} \mathrm{NaCl}$. The glandular stomach (fundus and antrum), duodenum, jejunum and ileum were isolated and mucosa from each segment scraped off with a glass slide. The mucosa was homogenised in $5 \mathrm{ml}$ deionised distilled water in a $7 \mathrm{ml}$ Dounce homogeniser (Kontes Glass Co., Vineland, NJ, USA) with 10 strokes of a loose-fitting (Type A) pestle, followed by 10 strokes 
of a tight-fitting (Type B) pestle. A $1 \mathrm{ml}$ aliquot was taken for measurement of ${ }^{51} \mathrm{Cr}$ (Gamma 7000 Counter; Beckman). Bismuth concentration was measured by flameless atomic absorption spectrophotometry (Perkin Elmer, Model 703, equipped with an HGA-76 graphite furnace) essentially as described by Rooney, ${ }^{8}$ with bismuth (bismuth nitrate standard, BDH Chemicals, Poole, Dorset) as standard and expressed as $\mu \mathrm{mol}$ bismuth per gram homogenate protein. Protein was measured by a modified Folin-Lowry method, with bovine serum albumin, fraction V, Sigma Chemical Co, Poole, Dorset, UK, as standard. ${ }^{9}$ Paired Student's $t$ test was used for statistical analysis of comparisons of bismuth concentrations in the various tissues.

TIME COURSE OF BISMUTH ELUTION FROM GASTRIC AND DUODENAL MUCOSA

Three additional groups of rats were administered colloidal bismuth subcitrate in the drinking water over 24 hours as outlined above, and subsequently allowed to drink plain water for 24,48 , and 72 hours, respectively, before being killed. Homogenates from gastric antrum and duodenum were prepared and bismuth measured as previously described. Values were corrected for minor variations in total bismuth intake by each animal. Statistical comparison between the groups was made with the use of two-tailed Student's $t$ test.

\section{SUBCELLULAR FRACTIONATION EXPERIMENTS}

This was examined in duodenal enterocytes by isopycnic sucrose density centrifugation and microanalysis of organelle marker enzymes, based on the method described by Peters. ${ }^{10}$ Rats were given colloidal bismuth subcitrate as a $50 \mathrm{mg} / \mathrm{ml}$ solution in the drinking water for 24 hours, and then killed. A higher dose was chosen than that used in the uptake experiments, in order to overcome the dilution effect inherent in the fractionation procedure and to ensure measurable concentrations of bismuth in the subcellular fractions. Duodenal enterocytes were isolated from sacs of duodenal intestine according to Peters and Shio, ${ }^{11}$ utilising hyaluronidase (EC 3.2.1.35) and gentle kneading to dislodge the enterocytes from the basement membrane, with subsequent washing of the cell suspension. The enterocytes were immediately transferred to $5 \mathrm{ml}$ ice-cold sucrose solution $(0.25$ $\mathrm{mol} / \mathrm{l})$ containing disodium ethylenediaminetetraacetic acid $\left(\mathrm{Na}_{2}\right.$ EDTA, $\left.1 \mathrm{mmol} / \mathrm{l}, \mathrm{pH} 7 \cdot 4\right)$ and ethanol $(22 \mathrm{mmol} / \mathrm{l})$. The tissue was disrupted on ice in a $7 \mathrm{ml}$ Dounce homogeniser with 10 strokes of pestle A and 10 strokes of pestle B. Approximately $4.5 \mathrm{ml}$ homogenate were layered onto a $28 \mathrm{ml}$ linear sucrose density gradient from $1.05-1.28 \mathrm{~g} / \mathrm{ml}$ resting on a $6 \mathrm{ml}$ sucrose $1.32 \mathrm{~g} / \mathrm{ml}$ in a Beaufay automatic zonal rotor. All solutions contained $1 \mathrm{mmol} / \mathrm{l}, \mathrm{Na}_{2}$ EDTA, pH 7.4 and $22 \mathrm{mmol} / \mathrm{l}$ ethanol. The rotor was then accelerated to $35000 \mathrm{rev} / \mathrm{min}$ for $35 \mathrm{~min}$ and then decelerated to $8000 \mathrm{rev} / \mathrm{min}$. The resulting gradient was displaced with nitrogen and 15 fractions collected into tared tubes. After reweighing, the density of each fraction was estimated indirectly with an Abbé refractometer.

Bismuth concentrations and activities of organelle marker enzymes were assayed in each tube and the data presented as frequency-density histograms, as described by Leighton et al. ${ }^{12}$ The histograms were plotted over a density scale (expressed in $\mathrm{g} \mathrm{cm}^{-3}$ of sucrose) and divided into sections of equal density increments. The ordinate expresses the frequency within the corresponding span of density. The lightest fractions (density $\leqslant 1 \cdot 10 \mathrm{~g} \mathrm{~cm}^{-3}$ ) reflect mainly soluble activity remaining in the starting layer, and were plotted over an arbitrary density span of $1.05-1 \cdot 10 \mathrm{~g} \mathrm{~cm}^{-3}$. This region, containing the cytosolic enzymes, is separated from the remainder of the gradient (in which the particulate organelle marker enzymes are found) by a vertical line (Fig. 1). The subcellular localisation of bismuth was determined by comparing its density 'profile' with that of marker enzymes from the various intracellular organelles. In separate experiments, mucosal scrapings were homogenised in sucrose medium containing the selective membrane perturbant digitonin (Sigma Chemical Co), $1 \mathrm{mg} / \mathrm{ml}$. Activities of alkaline phosphatase, EC 3.1.3.1 (brush border, membrane); $\mathrm{Zn}^{2+}$-resistant $\alpha$ glucosidase, EC 3.2.1.20 (brush border membrane); lactate dehydrogenase, EC 1.1.1.27 (cytosol); Nacetyl- $\beta$-glucosaminidase, EC 3.2.1.30 (lysosomes); succinate dehydrogenase, EC 1.3.99.1 (mitochondria); catalase EC 1.11.1.16 (peroxisomes); 5'-nucleotidase, EC 3.1.3.5 (predominantly basolateral membrane) were assayed essentially as described by Peters. ${ }^{10}$

\section{Results}

BISMUTH UPTAKE ALONG GASTROINTESTINAL TRACT

The results are summarised in the Table. In the colloidal bismuth subcitrate-treated animals, bismuth was detected in all mucosal segments. There was no difference between gastric fundus and antrum but bismuth uptake by the small intestinal mucosa was substantially greater than by gastric mucosa. There were no regional differences in bismuth concentration along the small intestine. In none of the homogenates was the ${ }^{51} \mathrm{Cr}$ more than $4 \%$ above background levels, indicating negligible 


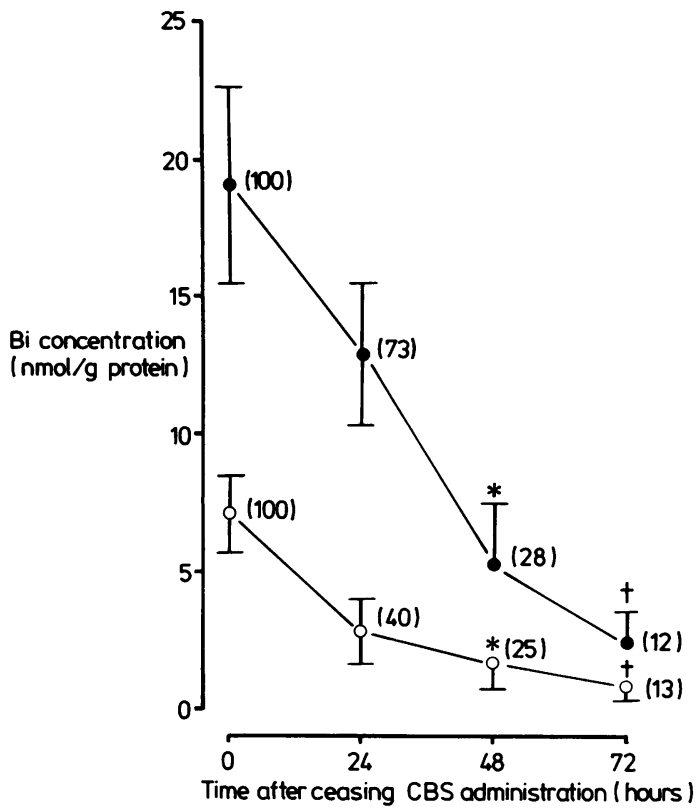

Fig. 1 Bismuth concentrations (mean $\pm S E$ ) in mucosal homogenates $(n=5)$ from rat duodenum (O) and gastric antrum (O) at 0, 24, 48, and 72 hours after a 24 hour period of oral colloidal bismuth subcitrate. Numbers in parentheses represent percentages of the initial bismuth concentration. Statistical analysis: ${ }^{*} p<0.05 ; \dagger p<0.02$, compared with concentrations at time 0 hours (Student's $t$ test).

binding of the non-absorbable marker. This minimises the possibility of non-specific adsorption of luminal contents (and hence bismuth) to the mucosal surface and ensures that any bismuth detected is bound to, or taken up by, the epithelial cells.

TIME COURSE OF BISMUTH ELUTION FROM MUCOSA Bismuth both in gastric antral and duodenal

Table Bismuth uptake by gastrointestinal mucosal segments in colloidal bismuth subcitrate-treated rats

\begin{tabular}{ll}
\hline Gastric fundus & $8 \cdot 85 \pm 1 \cdot 00$ \\
Gastric antrum & $7 \cdot 23 \pm 1 \cdot 5$ \\
Duodenum & $19 \cdot 2 \pm 3 \cdot 7^{*}$ \\
Jejunum & $26 \cdot 9 \pm 2 \cdot 4 \dagger$ \\
Ileum & $22 \cdot 4 \pm 2 \cdot 2 \dagger$ \\
\hline
\end{tabular}

Bismuth assayed in five animals (mean $\pm \mathrm{SE}$ ) $\mathrm{nmol} / \mathrm{g}$ protein. Control animals $(n=5)$ were similarly studied and contained less than $0.05 \mathrm{nmol} / \mathrm{g}$ protein.

Statistical analysis compares gastric antrum with each small intestinal segment: ${ }^{*} \mathrm{p}<0 \cdot 05 ; \dagger \mathrm{p}<0.001$ (paired $t$ test). mucosae, showed a progressive decline over the 72 hour period of the study (Fig. 1). By 72 hours, only approx $10 \%$ of the initial bismuth concentrations were detected.

\section{SUBCELLULAR DISTRIBUTION OF BISMUTH IN DUODENAL MUCOSA}

The sucrose density gradient distributions of bismuth and several organelle marker enzymes in duodenal homogenates are shown in Fig. 2. The distribution of bismuth is bimodal, with a soluble component corresponding to the cytosolic marker, lactate dehydrogenase, and a broad particulate peak of model density $1.23 \mathrm{~g} / \mathrm{ml}$ corresponding to the brush border membrane markers, alkaline phosphatase and $\mathrm{Zn}^{2+}$-resistant $\alpha$-glucosidase.
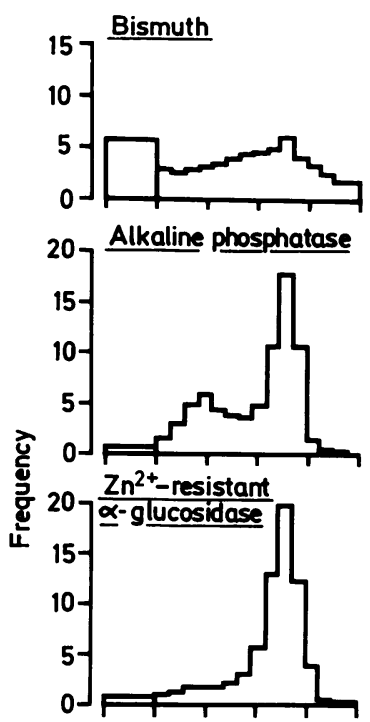

15. Lactate dehydrogenase

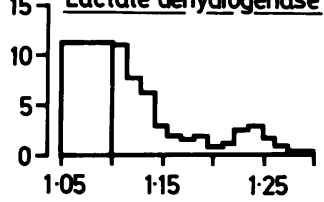

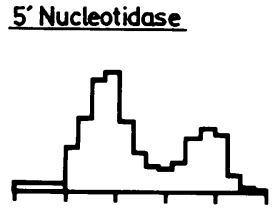
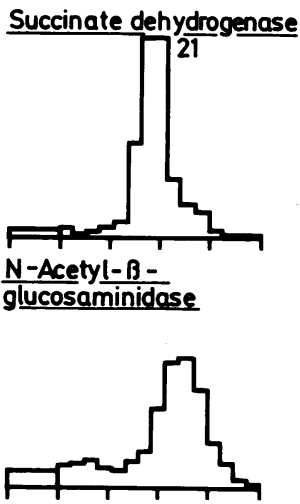

Catalase

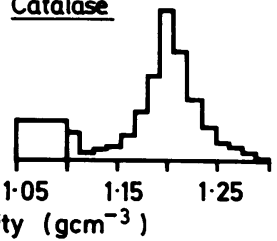

Fig. 2 Isopycnic centrifugation of rat duodenal enterocytes. Graphs show frequency-density histograms for bismuth and the principal organelle marker enzymes. Frequency (mean of two experiments) is defined as the fraction of total recovered activity in a fraction divided by the density span covered. The fractions spanning densities $1.05-1.10 \mathrm{~g} \mathrm{~cm}^{-3}$ have been pooled and represent presumed soluble activity remaining in the sample layer. Bismuth recovery is $89 \%$. See Methods for further details. 
There is little separation between these enzymes, however, and that of the lysosomal marker $\mathrm{N}$-acetyl$\beta$-glucosaminidase. To exclude the possibility of lysosomal accumulation of bismuth, further experiments were performed homogenising the mucosa in the presence of digitonin which forms high-density complexes with membrane-bound cholesterol. Digitonin produced an increase in modal density of the particulate bismuth from $1.23 \mathrm{~g} / \mathrm{ml}$ to $1.27 \mathrm{~g} / \mathrm{ml}$ (Fig. 3). This pattern is characteristically seen with the cholesterol-rich brush border membrane and contrasts markedly with the labilising effect of digitonin on lysosomal membranes. ${ }^{10}$ These data are highly suggestive of a dual localisation (cytosol and brush border membrane) of bismuth within duodenal enterocytes.

\section{Discussion}

Colloidal bismuth subcitrate $\left(\mathrm{De} \mathrm{Nol}^{\circledR}\right)$ is an effective agent in promoting the healing of chronic peptic ulcers. ${ }^{1-3}$ Although its mode of action is incompletely understood, there is evidence that it acts topically as a diffusion barrier to hydrochloric acid at the ulcer base ${ }^{13}$ and it impedes $\mathrm{H}^{+}$backdiffusion into gastric mucosa. ${ }^{14}$ Its efficacy requires an acid $\mathrm{pH}$, at which it forms an insoluble precipitate. ${ }^{13}$ It has been widely assumed that the bismuth is not absorbed from the gastrointestinal tract after administration of colloidal bismuth subcitrate. ${ }^{15}$ Studies in laboratory animals, however, reveal detectable concentrations of

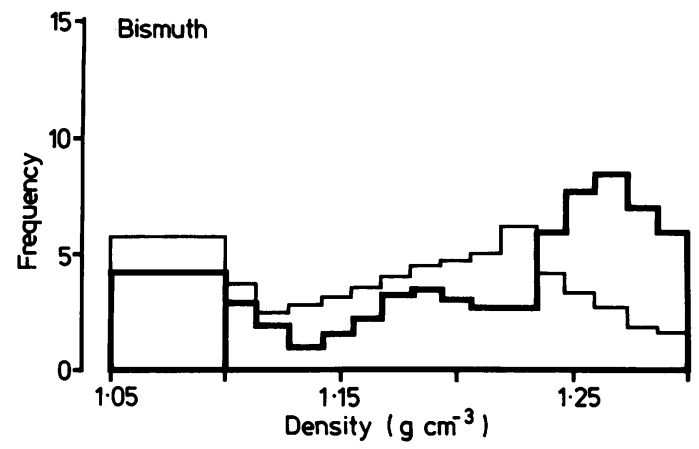

Fig. 3 Isopycnic centrifugation of rat duodenal enterocytes showing the effect of digitonin on the distribution of bismuth. Details are given in Fig. 2. The frequency-density distribution of bismuth in control (-) and digitonin-treated (-) homogenates is shown. Digitonin resulted in a shift of the particulate peak from a modal density of $1.23 \mathrm{~g} \mathrm{~cm}^{-3}$ to $1.27 \mathrm{~g} \mathrm{~cm}^{-3}$, with no increase in the activity of the soluble component. The data represent the mean of two experiments. bismuth in several organs after long term high dose colloidal bismuth subcitrate administration. ${ }^{56}$ Low (sub-toxic) bismuth concentrations have also been reported in the blood and urine of human volunteers and patients with peptic ulcers after colloidal bismuth subcitrate therapy for several weeks. ${ }^{4}$ It is clear, therefore, that some gastrointestinal absorption of bismuth occurs after administration of colloidal bismuth subcitrate.

The results of the present study show uptake of bismuth by both gastric and small intestinal mucosa within 24 hours of starting colloidal bismuth subcitrate administration. This represents intramucosal uptake and not simply adherence of bismuth to the surface mucus, as the tissue was meticulously rinsed and no measurable amounts of the non-absorbable tracer could be detected in the homogenates. It should be pointed out, however, that the doses of colloidal bismuth subcitrate used in this study were high, and that gastrointestinal luminal concentrations of bismuth in this study almost certainly exceeded those achieved therapeutically in ulcer patients.

The relatively lower bismuth concentrations, in gastric compared with small intestinal mucosa, may have resulted from different yields of mucosa and submucosa during tissue harvesting. A more likely explanation, however, is that precipitation of colloidal bismuth subcitrate occurred within the acidic gastric lumen. In contrast, the $\mathrm{pH}$ within the intestinal lumen is generally above 4.5 (the $\mathrm{pH}$ below which precipitation of colloidal bismuth subcitrate occurs). Wieriks ${ }^{5}$ found bismuth to be present in the stomach, duodenum, and caecum of rats and dogs after several months of daily dosing with colloidal bismuth subcitrate. In that study, however, bismuth content of the entire wall of the intestine (including adherent mucus) was measured and no comment made about mucosal bismuth concentration.

In the present study, the bismuth content of antral and duodenal mucosa fell progressively over 72 hours after cessation of colloidal bismuth subcitrate administration. This finding could be explained either by gradual systemic absorption of bismuth from the mucosa, or by shedding of bismuth containing cells or their constituents into the lumen during crypt-to-villus maturation. ${ }^{16}$ Although blood bismuth concentrations were not measured in the present study, the results of the subcellular fractionation experiments clearly show the presence of bismuth within duodenal enterocytes from which it could be absorbed into the circulation.

An electron microscopic study by Coghill ${ }^{17}$ suggests that bismuth is phagocytosed by duodenal epithelial cells and accumulates in multivesicular 
bodies (possibly lysosomes). Our findings are more indicative of a localisation to the brush border membrane and cytosol of the enterocyte. Accumulation in the brush border membrane could be in keeping with claims that colloidal bismuth subcitrate stimulates mucus glycoprotein secretion and increases the thickness of the glycocalyx,${ }^{18}$ though these findings have been disputed. ${ }^{19}$ Moreover, accumulation of bismuth within gastrointestinal mucosal cells may exert as yet unknown influences on cellular functions. Heavy metals are well-known modifiers of enzymes, and for example, bismuth has been shown to inhibit human intestinal alkaline phosphatase activity. ${ }^{20}$ The anti-ulcer effects of colloidal bismuth subcitrate may in fact be more complex than simple precipitation within the ulcer crater and further studies of the effect of this drug, and of bismuth in particular, on brush border structure and function are clearly indicated.

The expert technical assistance of P White, P Leach, and $\mathrm{K}$ Raja is gratefully acknowledged. We thank the Postgraduate Committee, University of Sydney and Wellcome Trust (DS) and Brocades (Great Britain) Ltd (DJM) for financial support.

\section{References}

1 Kang JY, Piper DW. Cimetidine and colloidal bismuth in treatment of chronic duodenal ulcer. Comparison of initial healing and recurrence after healing. Digestion 1982; 23: 73-79.

2 Tytgat GNJ, van Bentem N, van Olffen G, Dekker W, Rutgeerts L, de Boer J. Controlled trial comparing colloidal bismuth subcitrate tablets, cimetidine and placebo in the treatment of gastric ulceration. Scand $J$ Gastroenterol 1982; 17: suppl 80: 31-8.

3 Hamilton I, Worsley BW, O'Connor HJ, Axon ATR. Effects of tripotassium dicitrate bismuthate (TDB) tablets or cimetidine in the treatment of duodenal ulcer. Gut 1983; 24: 1148-51.

4 Lee SP. Studies on the absorption and excretion of tripotassium dicitrato-bismuthate in man. Res Commun Chem Pathol Pharmacol 1981; 34: 359-64.

5 Wieriks J. Hespe W, Jaitly KD, Koekkoek PH, Lavy U. Pharmacological properties of colloidal bismuth. Scand J Gastroenterol 1982; 17: suppl 80: 11-6.
6 Lee SP, Lim TH, Plybus J. Clarke AC. Tissue distribution of orally administered bismuth in the rat. Clin Exp Pharmacol Physiol 1980; 7: 319-24.

7 Mackenzie RD, Anwar RA, Byerrum RV, Hoppert CA. Absorption and distribution of $\mathrm{Cr}^{51}$ in the albino rat. Arch Biochem Biophys 1959; 79: 200-5.

8 Rooney RC. Determination of bismuth in blood and urine. Analyst 1976; 101: 749-52.

9 Schacterle GR, Pollack RL. A simplified method for the quantitative assay of small amounts of protein in biologic material. Anal Biochem 1973; 51: 654-5.

10 Peters TJ. Analytical subcellular fractionation of jejunal biopsy specimens: methodology and characterisation of the organelles in normal tissue. Clin Sci Mol Med 1976; 51: 557-74.

11 Peters TJ, Shio H. Analytical subcellular fractionation studies on rat liver and on isolated jejunal enterocytes with special reference to separation of lysosomes, peroxisomes and mitochondria. Clin Sci Mol Med 1976; 50: 355-66.

12 Leighton F, Poole B, Beaufay $\mathrm{H}$ et al. The large-scale separation of peroxisomes, mitochondria and lysosomes from livers of rats injected with Triton WR 1338. J Cell Biol 1968; 37: 482-513.

13 Lee SP. A potential mechanism of action of colloidal bismuth subcitrate: diffusion barrier to hydrochloric acid. Scand J Gastroenterol 1982; 17: suppl 80: 17-21.

14 Mehta JG. Morrissey SM. Effect of De Nol on the $\mathrm{H}^{+}$ ion back diffusion in the guinea pig stomach. Proc Int Union Physiol Sci 1983; 15: 423.

15 Wilson TR. The pharmacology of tripotassium dicitratobismuthate (TDB). Postgrad Med J 1975; 51: suppl 5: 18-21.

16 Alpers DH. Protein turnover in intestinal mucosal villus and crypt brush border membranes. Biochem Biophys Res Commun 1977; 75: 130-5.

17 Coghill SB, Hopwood D, McPherson S, Hislop S. The ultrastructural localization of $\mathrm{De}$ Nol (Colloidal tripotassium dicitratobismuthate-TDB) in the upper gastrointestinal tract of man and rodents following oral and instrumental administration. J Pathol 1983; 139: 105-14.

18 Moshal MG, Gregory MA, Pillay C, Spitaels JM. Does the duodenal cell ever return to normal? A comparison between treatment with cimetidine and De Nol. Scand J Gastroenterol 1979; 14: suppl 54: 48-51.

19 Giraud AS, Newton AS, Korman MG, Yeomans NB. Mode of action of tripotassium dicitrato bismuthate (TDB): effect of glyocalyx of duodenal enterocytes. Clin Exp Pharmacol Physiol 1982; 9: 571.

20 Komoda T, Sonoda M, Ikeda M, Hokari S, Sakagishi Y. Inhibition of alkaline phosphatase by bismuth. Clin Chim Acta 1981; 116: 161-9. 